\title{
Assessment and mechanism of variations in pubertal timing in internationally adopted children: a developmental hypothesis
}

\author{
F Dominé, A-S Parent, G Rasier, M-C Lebrethon and J-P Bourguignon \\ Division of Pediatric Endocrinology and Adolescent Medicine, Department of Pediatrics, Center of Cellular and Molecular Neurobiology, University of Liège, \\ University Hospital (CHU), B-400O Liège (Sart-Tilman), Belgium
}

(Correspondence should be addressed to J-P Bourguignon; Email: jpbourguignon@ulg.ac.be)

\begin{abstract}
During the past decades, children migrating for international adoption have increased in number, creating an original condition of dramatic environmental change during development. In several countries, cohorts of these subjects have been shown to experience a global advancement in age at the onset of puberty, and sexual precocity is seen more frequently than in other conditions. Such early or precocious development has been assessed in relatively small cohorts or individual patients using welldefined physical indicators in comparison with updated references in the foster country. Family and adolescent evaluation of pubertal timing could allow for the study of large series of internationally adopted subjects. Also, this type of assessment integrates the physical changes of puberty with the adolescent changes in psychological and social functioning. The pathophysiological mechanisms leading to advancement of puberty in migrating children are still unclear and possibly involve several factors. In the present paper, we hypothesize that the sexual precocity in children migrating for international adoption could represent a developmentally programmed disorder resulting from cumulative anomalies in early remodeling of the central nervous system by communicational, social, nutritional, and hormonal inputs. There is some evidence that the deviations in those inputs can result in altered brain structure, particularly in the limbic system. We discuss the possible association with further disorders of developmental functions, such as cognitive, psychosocial, and sexual maturation. Along this hypothesis, some forms of idiopathic sexual precocity could result from dysfunction of one or several of the environmental programming factors, while other forms may involve predominantly genetic or familial factors.
\end{abstract}

European Journal of Endocrinology 155 S17-S25

\section{Introduction}

Evidence is accumulating that early life environment is, pre-, peri- and postnatally, a determinant of later physiological and pathological events (1). Among those life events, the timing of puberty has a unique place since it is directly linked with reproductive capacity, a crucial process for species survival that environmental conditions may affect. The secular changes in timing of puberty have been thought to result from postnatal environmental influences, especially nutrition (2). In this particular case (Fig. 1), the timing of maturation is related to nutritional cues, early maturation resulting from a positive balance and late maturation resulting from a negative balance. The excess positive balance and resulting hyperinsulinism and obesity in USA have been proposed to account for the advance in timing of puberty

This paper was presented at the 4th Ferring Pharmaceuticals International Paediatric Endocrinology Symposium, Paris (2006). Ferring Pharmaceuticals has supported the publication of these proceedings. in this country (3). Pre- and perinatal nutrition could also play an important role that can be opposed to postnatal effects, since intrauterine growth retardation (IUGR) is associated with a trend towards early maturation $(1,4-6)$. Small size at birth and elevated body mass index (BMI) SDS at 8 years are predictive of early menarche in girls (7).

A recent observation questioning about environmental factors is the elevated incidence of sexual precocity in internationally adopted children for which several pathophysiological mechanisms have been proposed (2). Gluckman and Hanson have suggested that both the secular trend and the trend towards early puberty in children who migrate for international adoption reflect adaptation mechanisms in an evolutionary perspective with two components: interaction of prenatal effects to advance puberty under poor conditions and childhood effects to advance puberty under enriched conditions (8). Such a concept is consistent with the two effects illustrated in Figure 1. Also, those authors emphasize that the evolutionary changes currently lead to a mismatch between 


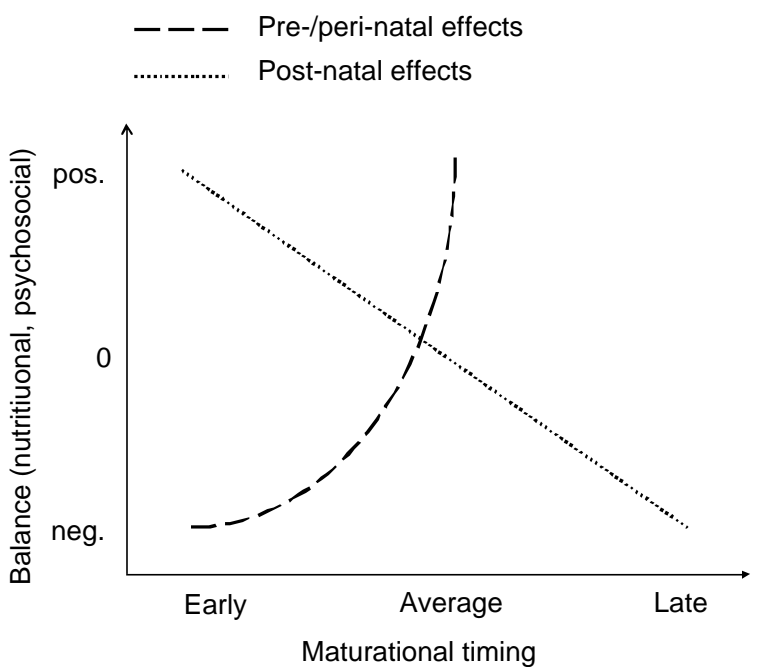

Figure 1 Schematic representation of the opposing effects of preand perinatal versus postnatal differences in nutritional and psychosocial balance on the timing of maturation.

relatively early physical maturation and late psychosocial maturation $(8,9)$. In the global context of adolescence, it is indeed important to consider the assessment of pubertal maturation through the integration of the physical changes together with the psychological and social correlates (10). The involvement of physical and psychosocial changes as a whole is also relevant to the self-assessment or family evaluation of variations in pubertal timing that could sometimes lead to a conclusion different from physician assessment. In this review, we will discuss the physical and global assessment of pubertal timing in internationally adopted children in Belgium as compared with pubertal timing in Belgian natives. Then, the mechanism of variations in pubertal timing in internationally adopted children will be examined in a developmental perspective and a pathophysiological hypothesis of disordered programming will be proposed.

\section{Assessment of variations in pubertal timing}

\section{Assessment of physical development}

When the clinical issue is the diagnosis of abnormal timing of the onset of puberty, the focus is on the most initial signs of pubertal development. In boys, the first sign of puberty is an increase in testicular volume above $3 \mathrm{ml}$, consistent with Tanner G2 stage $(11,12)$. However, this change can be observed by thorough evaluation during physical examination only $(11,13)$ and cannot be perceived by the subject himself. When taking history, there is no single reliable event that can be recalled to time male puberty. Voice deepening has been considered though it is a relatively variable and progressive change. In girls, the earliest manifestation of puberty is acceleration in height velocity. However, this is rarely ascertained clinically because several accurate height measurements are required each year (14). Also, the subjects and families do not become aware of the subtle initial growth acceleration as opposed to the peak height velocity that they usually notice. Tall stature could bias growth perception though this is not a matter of concern in migrating adoptees, who are usually below average height. The commonly used marker of the onset of female puberty is thelarche i.e. the first appearance of breast development defined as Tanner B2 stage (11). During inspection, this marker is easily biased by fat tissue, which is a concern in some children who develop overweight after migration (2). The appearance of pubic hair or pubarche from which puberty is etymologically derived can be a misleading sign to evidence pituitarygonadal maturation, particularly in girls. Pubarche is dependent initially on adrenal and testicular androgens in boys and adrenal androgens in girls. This developmental increase in adrenal androgen secretion is referred to as adrenarche and occurs independent of the pituitary-gonadal maturation or gonadarche (15-17).

Menarche, the occurrence of first menstruation is a unique but late marker of female puberty (12). The variations in menarcheal age in a given population can be assessed directly and preferably through the status quo method by asking girls in different age groups whether they had first menses or not. Retrospective assessment through the recall method leads to comparable data in some conditions (18). However, a longer recall period (19) and socio-economic or cultural biases (20) can result in a loss of accuracy. In the individual subject or patient, only a recall assessment is possible, with the same biases as of a population study. The menarcheal age is highly significantly correlated with age at the appearance of breast buds (12) and is therefore considered to be an indicator of the timing of onset of puberty. However, others have reported that the ages at the onset of breast development and menarche are not strictly correlated (21) due to possible confounding factors. Among these factors, a decrease in duration of puberty or time period between $\mathrm{B} 2$ stage and menarche has been observed in subjects with late onset of puberty when compared with early onset (21-23). Menarche could provide information different from breast budding, since the former is the endpoint of a complex sequence of maturational events, whereas the latter results more simply from onset of estrogenic action. Also, any factor such as environmental estrogens could stimulate breast development independent of hypothalamic-pituitaryovarian maturation and thus account for dissociation between the ages at breast budding and menarche.

\section{Assessment of global development}

In some conditions (large number of distant subjects, refusal of genital exam etc.), pubertal development is 
not easily assessed by a professional, and self-evaluation by the subject or the parents must be considered. Moreover, self-perception and family perception of pubertal changes is important because it can influence the behavioral outcomes during adolescence. This is the bio-psychosocial perspective $(10,24)$. Self-assessment or family evaluation of development occurs as a global appraisal where various physical, psychological, and social changes are integrated (25). When single physical indicators such as pictures of the semiquantitative Tanner stages are used by adolescents to score pubertal development, self-assessment provides less reliable information than assessment by professionals (26-30). Several biasing factors have been shown to limit the validity of self-assessment of such pubertal characteristics: adiposity, ethnicity, and early or late timing (26-34). To overcome those limitations, integrative scoring systems have been proposed such as the Pubertal Developmental Scale (PDS) involving five items rated on a 4-point scale $(25,27)$. Another integrative approach has been to ask adolescents to rate the timing of puberty globally instead of rating individual pubertal signs (35). Both the PDS and the answer of adolescents to a global question on development versus peers have been shown to be valid approaches, fairly well correlated with physician assessment $(35,36)$. Discrepancies between assessment of pubertal timing by health-care professionals, children, and parents can arise from differences in concern about outcomes of pubertal development (37). When development is evaluated through questionnaires, the bias of parents and child concerns about sexual development and their reluctance to provide information on this matter (37) may influence the response rate. Accordingly, particular subgroups such as early maturers can be over- or under-represented among the responding families. When the above issues are considered in the context of international adoption, the biasing factors reach maximal levels: diversity of ethnicity, self-image after migration, school delay, exacerbated parental concerns, etc.

\section{The paradigm of internationally adopted children}

During the last decades, a new form of sexual precocity has been described in foreign children adopted from developing countries to Western Europe (review in (2)). The occurrence of early or precocious sexual maturation in such a unique situation of changing environment has been originally described in Indian girls adopted in Sweden (38). Subsequently, similar observations have been made in several European countries and children from various countries are involved (39-45). So far, there is only one similar report from the USA published in abstract form (46). In cohorts of foreign-adopted patients, the mean menarcheal age, which has been evaluated through questionnaires, is advanced to 10.5-12.0 years and the frequency of sexual precocity is increased by between 13 and $30 \%(38,40,43$, and 46). Thus, advanced puberty is a general feature of the whole cohort resulting in more frequent abnormal precocity as well (Fig. 2C). Additional evidence of early timing of puberty after foreign adoption comes from the observation of sexual precocity in such individual patients $(41,43)$, who are overrepresented (16-26\%) among the whole group of patients treated for central precocious puberty $(44,45)$. However, more cautious medical attention paid to the foreign-adopted children could contribute to overestimation of sexual precocity in comparison with children native to the foster country (47).

The children and adolescents native to Belgium provide the natural comparison basis for internationally adopted children fostered in this country. In Belgium, the average menarcheal age has remained remarkably stable around the age of 13 for the past 40 years $(48,49)$. This could mean that secular changes have come to an end in this country. However, a detailed evaluation (inspection and palpation) of the early physical markers of pubertal development indicates subtle skewing (Fig. 2B) of the age distribution of starting breast development towards early timing (49). A similar observation is made regarding the onset of testicular volume increase in boys (49). Thus, it appears that the dynamics of pubertal development are evolving in both internationally adopted children and Belgian natives.

In a bio-psychosocial perspective, the early maturers represent a subgroup of subjects feeling globally ahead of their peers. This subgroup is particularly large among the internationally adopted children (Fig. 2C) and larger than the group of patients diagnosed with

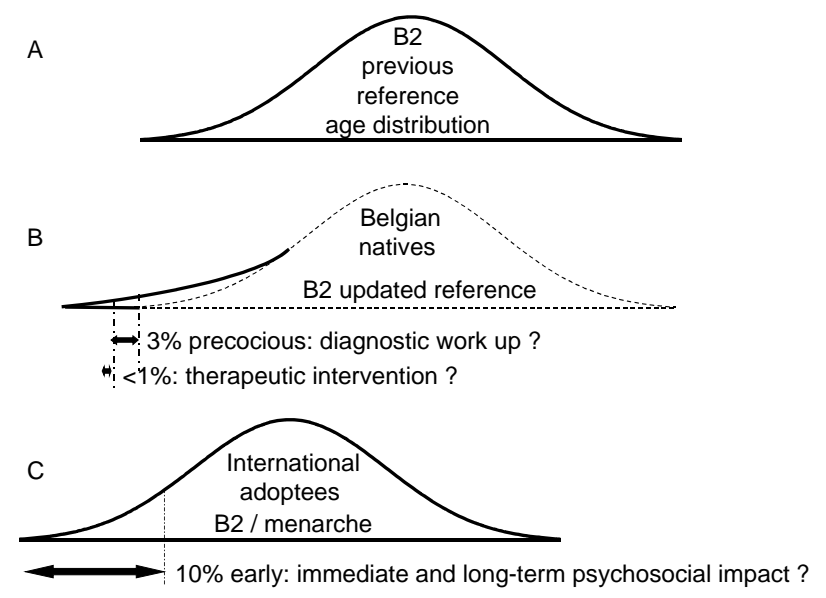

Figure 2 Schematic representation of age distribution of pubertal timing in different conditions. (A) Reference population in Belgium, 1960s; (B) reference population in Belgium, 2000s; B2: Tanner's stage 2 of breast development; and (C) cohort of internationally adopted children. 
sexual precocity (Fig. 2B) based on classical pediatric endocrine criteria. The issue is whether immediate and long-term psychosocial correlates of advanced puberty are a concern in the precocious subgroup mainly, or should be considered in the early subgroup as well. Large surveys on adolescent exploratory behaviors have shown that the early maturers are more frequently involved $(25,50,51)$. Longitudinal studies in adulthood confirm such findings (52). Moreover, the migrants have been found at higher risk than the native adolescents in Sweden (53). All together, the available data indicate that the early maturing group deserves particular attention, while it is not known whether early puberty is a causal factor for risk behaviors per se or whether early puberty and risk behaviors share common determinants.

\section{Pubertal timing in a developmental mechanistic perspective}

In this section, the evidence discussed is that some factors account for early reshaping of some central nervous system (CNS) regions and programming of physiological events later in life. Then, the possible role of anomalies in those factors in the pathogenesis of sexual precocity, together with other disorders in internationally adopted children, is discussed.

\section{Physiological programming}

The maturational processes of cognitive, psychosocial, and biological functions are controlled by genetic determinants. The timing of puberty is not an exception since $70-80 \%$ of its variance is explained by genetic factors (review in (2)). The genetically determined characteristics are reshaped by some body and environmental clues (Fig. 3) that can modify the programming of maturational processes during critical prenatal and early postnatal periods of rodent or primate life (1). The timing of puberty is one among several life events, potentially influenced by such a program during early life $(8,9)$. This remodeling can involve changes in structural and functional organization of the CNS. Some of those changes are listed below, particularly those occurring in the limbic system, which appears to be affected by different factors (Fig. 3). In this overview, it will not be possible to discuss separately and in detail the available data obtained in animal and human models. The purpose is to integrate some of the effects of different factors into a common developmental pathophysiological mechanism.

There is evidence that early social experiences of attachment and emotional communication can dramatically affect the development of the right brain hemisphere, especially the limbic system $(54,55)$. This system contributes to the control of variations in autonomic responses to stress situations that are known to influence hypothalamic function $(56,57)$.

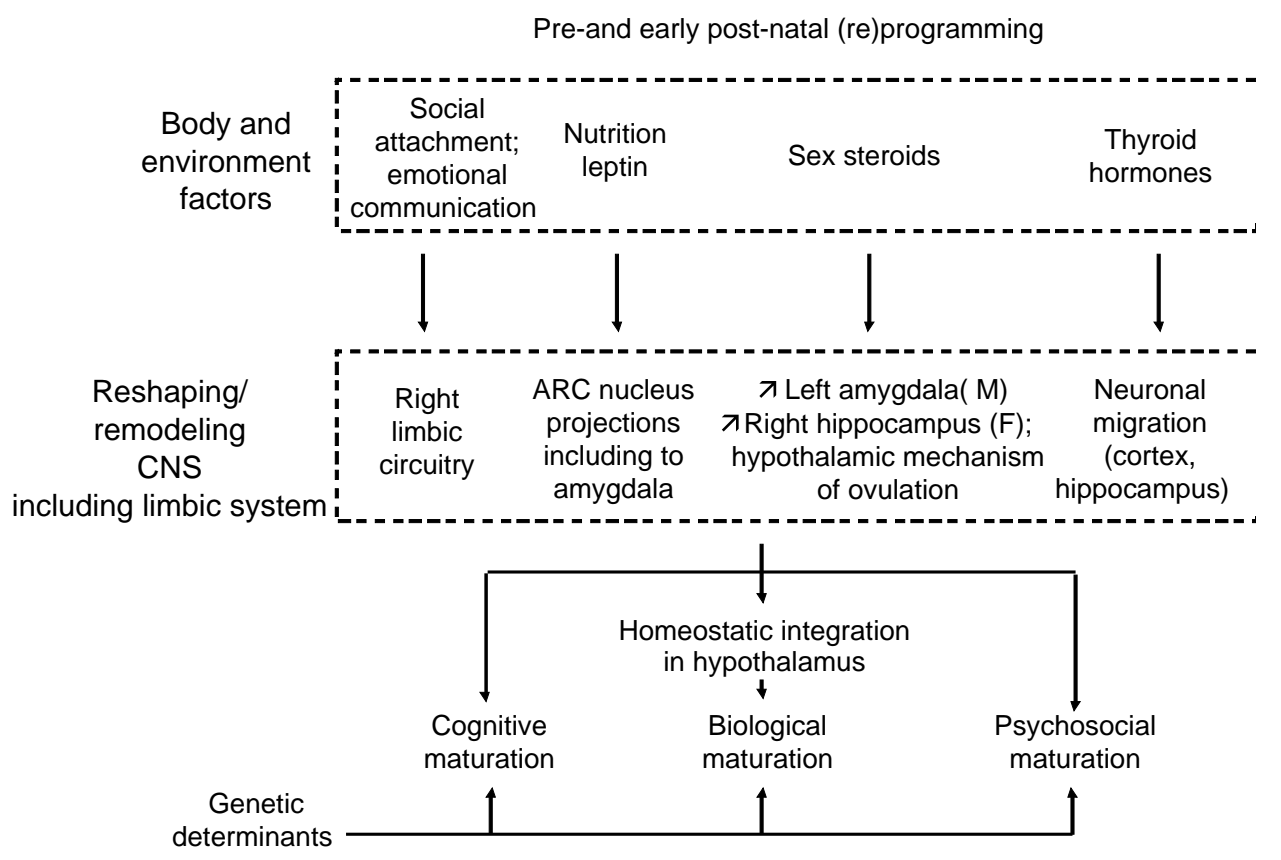

Figure 3 During the critical prenatal and early postnatal periods of life when the central nervous system (CNS) shows important development and adaptation capacities, several body and environmental factors can physiologically reshape the CNS, particularly the limbic system, with resulting consequences on the maturational processes that depend on the CNS, including the hypothalamic control of energy balance and sexual maturation. ARC, arcuate; M, male; F, female. 
Nutrition involves numerous factors that can influence brain reshaping and life events either directly or through modulation of nutrition-dependent hormones such as insulin, insulin-like growth factor-I, and leptin (review in (2)). There could be a critical postnatal period for nutritional priming of maturation, as suggested by observations in healthy boys and girls (5, 58). Developmentally, leptin could be a key factor linking nutrition and the brain. This peptide can influence the development of the neuronal circuitry projecting from the arcuate nucleus in the hypothalamus to other brain structures, including the amygdala in the limbic system $(59,60)$. Sex steroids are also an important component of brain remodeling. Magnetic resonance imaging of the adolescent brain shows that frontal gray matter volume shows a reduction starting at about 11 years in girls and 12 years in boys (61). More specifically, in the limbic system, boys show an increased development of the left amygdala, whereas girls show increased development of the right hippocampus (62). The hypothalamic control of ovulation is a precise maturational mechanism that is also affected by sex steroids during a critical perinatal programming period in different mammal species (63). Finally, thyroid hormones play a critical role during early brain development $(64,65)$. Again, the limbic system is involved, since neuronal migration in the cortex as well as the hippocampus is affected by thyroid hormones. Dendritic arborization and synaptogenesis in the cerebellum are other important aspects.

\section{Disordered programming and sexual precocity}

As shown in Figure 4, there are several possible early developmental disturbances that can occur during early life, particularly in internationally adopted children, that could account for several disorders later in life, including sexual precocity. A critical age window for this programming effect is consistent with the observation that precocious menarche $(<10$ years) is more common in Indian girls who arrived Sweden between 3 and 6 years than in those who migrated before the age of 2 (38). Proos has reported that in foreign adopted children, earlier menarche is correlated with later age during immigration and faster catch-up in height and weight after immigration (66). However, in a multiple linear regression analysis, he finds that menarcheal age is associated with height at immigration, but not with age.

Chronic early abuse or neglect and impaired attachment have been shown to result in structural CNS anomalies including atrophy of the amygdala (54, 55 ) and reduced size of the corpus callosum (67). Those stressful conditions are unfortunately very common before international adoption $(68,69)$ and probably involve different stress components. In a study of 65 Romanian adoptees in USA, Johnson et al. find that only $15 \%$ of them were mentally and physically healthy at arrival (70). These authors have observed that growth failure is directly correlated with the duration of institutionalization. Every 3 months of life in an orphanage results in a loss of 1 month in height age.

Pregnancy and earlypost-natal life in adverse conditions before international adoption

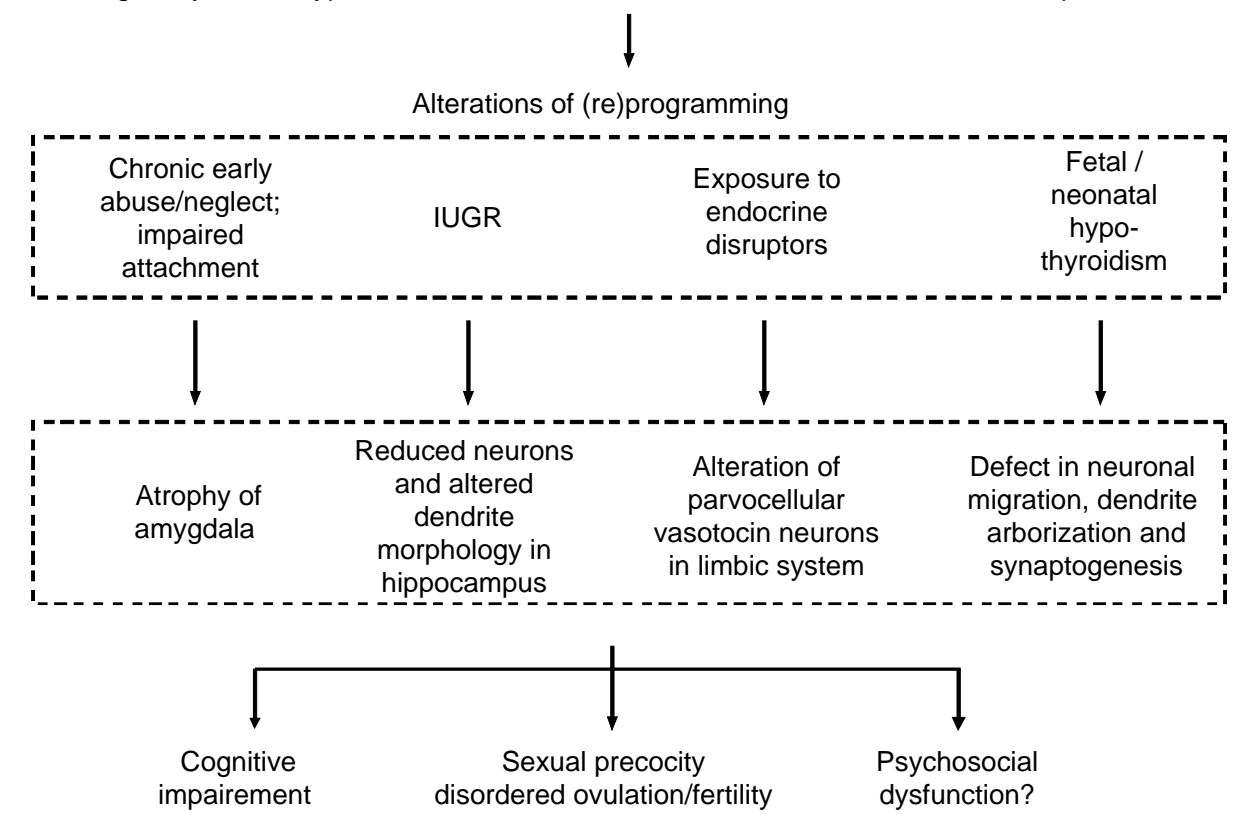

Figure 4 Alterations in different programming factors (communication, nutrition, sex steroids, and thyroid hormones) during prenatal or early postnatal life, when the brain still shows important development and plasticity could result in common impairment of cognitive, reproductive, and psychosocial functions later in life. Consistent with such a pathophysiological hypothesis, structural central nervous system anomalies such as those described in the limbic system could be shared by different disorders. IUGR, intrauterine growth retardation. 
They also reported that weight is usually less compromised than height, suggesting that nutritional deprivation might play a less prominent role than other factors such as, genetics, prematurity, IUGR, medical illnesses, and stress. A catch-up growth is also noticed after adoption with a greater extent of recovery in children adopted before 18 months than those adopted at later ages (70). The heterogeneity of the neuroendocrine response to various acute stressors indicates that the stress components are signaling through specific pathways (71). Among the neuronal circuits involved, signaling through corticotropin-releasing factor and interleukin-1 may be particularly important (72). It could be that, in foreign migrating children, withdrawal from a stressful environment contributes to potentiation of maturation though some stress may result from the adoption and migration processes as well. The latter hypothesis is consistent with the observation that pubertal development is early in conditions of stressful rearing and insecure attachment to parents $(73,74)$. The above considerations on the role of psychosocial conditions fit with the mechanistic concept proposed by Schulz and Sisk (75), though they report that psychosocial remodeling still occurs during adolescence in the Syrian hamster. The role of psychosocial factors can be crucial as compared with nutritional factors. Recently, it has been reported that growth retardation in developing countries before 5 years is associated with cognitive and educational deficits in late adolescence, which are reduced by psychosocial stimulation, but not nutritional supplementation at young ages (76).

In adopted children migrating to Western Europe or USA, the likelihood of increased incidence of IUGR is suggested by the Swedish cohort study where $80 \%$ of 37 children with known birth weight were below $2.5 \mathrm{~kg}$ (77). Unfortunately, information on birth weight and maternal risk factors for IUGR is lacking in the other studies. As reviewed recently by Ibanez and de Zegher (78), there is evidence that IUGR can be linked with early puberty and disordered ovulation. Studies in the guinea pig show that IUGR causes selective reduction in neuron number and alteration in dendrite morphology in the hippocampus $(79,80)$. Human magnetic resonance imaging studies show reduction in cortical gray matter in infants with IUGR (81). Postnatal nutrition and catch-up recovery from wasting has been thought to possibly contribute to early maturation in internationally adopted children $(2,39,47,66,68)$. Quite interestingly, such a natural history of postnatal growth creates conditions that possibly worsen the effects of disordered prenatal programming. Such a conclusion is drawn by Barker, who reports that impaired growth in infancy and rapid childhood weight gain exacerbate the metabolic effects of impaired prenatal growth (6). In order to mimic catch-up growth after immigration in formerly deprived foreign children, early underfeeding and re-feeding has been used in the rat and the effects have been studied on hypothalamic glutamate neurotransmission, which is a major trigger of pulsatile gonadotropin-releasing hormone (GnRH) secretion $(2,39)$. An acceleration of maturation of the glutamate receptor-dependent secretion of GnRH occurs after re-feeding and is maximal at a particular age period postnatally (39). These data suggest the involvement of hypothalamic glutamate receptors in the pathophysiology of that form of sexual precocity. While the impact of nutritional deprivation and restoration after migration may be crucial in some foreign children who develop sexual precocity, others have normal weight and height at arrival (2), suggesting the role of other factors. Interestingly, therapy with the insulin sensitizer metformin prevents the advancement in menarcheal age in low birth weight girls or in girls with premature pubarche $(82,83)$. Neonatal leptin treatment is capable of reversing the long-term detrimental metabolic consequences of fetal undernutrition (84).

Besides the physiological early role of sex steroids in the CNS, including sexual maturation and reproduction $(85$, 86), the involvement of endocrine-disrupting chemicals (EDCs) has raised interest $(2,63)$ after we reported that internationally adopted children with sexual precocity have detectable serum levels of a long-lasting residue of the insecticide DDT (44). The mechanism can involve potentiation of maturation of pulsatile secretion of hypothalamic GnRH $(44,63)$. Several studies indicate that EDCs including xenoestrogens and phytoestrogens may interact with brain development, directly or through alterations of thyroid hormone status $(65,87-89)$. It is tempting to link the programming effect of sex steroids with sexual dimorphism in sexual precocity, since, in the foreign-adopted children precocious puberty was seen much more frequently in girls than in boys $(38-41,43$, $44,46)$. Such a sexual dimorphism might reflect the general and unexplained female preponderance of idiopathic central precocious puberty (2). However, a precise cause influencing specifically the female endocrine system cannot yet be excluded. The observation of a sexually dimorphic early reshaping of some CNS structures such as the limbic system $(61,62)$ is consistent with a possible early CNS programming of the female predisposition to develop earlier puberty than males. However, it is still unclear whether that structural sexual dimorphism in the human limbic system depends directly on genetic factors and sex chromosomes or on hormonal factors such as sex steroids (90). The latter mechanism is supported by estrogen organizational effects on the limbic parvocellular system during embryonic life in the quail $(91,92)$. A female predisposition to early onset of puberty is found to be associated with IUGR (93). Non-reproductive behaviors are also sexually dimorphic and provide a basis for endocrine disruption of other functions such as cognitive and psychosocial behaviors (94).

When taking place in prenatal and early postnatal life, thyroid disorders have detrimental consequences on cognitive function $(64,65,85)$. Precocious puberty is a 
rare intriguing complication of primary hypothyroidism that has been attributed to interaction of the markedly elevated thyroid stimulating hormone (TSH) with the follicle stimulating hormone receptor (95). However, sexual precocity has been reported to occur as well in the absence of elevated TSH, raising the issue of a neural mechanism (96). Damaged reproduction has appeared to be one of the most important long-term consequences of thyroid hormone insufficiency due to iodine deficiency (97). Though this type of deficiency has not been documented so far in children migrating for international adoption, many among them come from countries where iodine deficiency is endemic.

\section{Conclusion}

Puberty is a developmental biological process that is integrated with the complex psychosocial maturation of adolescence. Previous studies have highlighted the facilitatory effects of pre- and perinatal nutritional deficit and postnatal nutritional excess in early puberty, two factors, which can be combined in children migrating from developing countries. Here, a pathophysiological hypothesis is proposed that involve disorders of early programming effects and CNS reshaping by emotional conditions/attachment, nutrition and related hormones, sex steroids, and thyroid hormones to account for sexual precocity, possibly associated with other disorders, in internationally adopted children. Along this concept, such disorders would be more common after late migration, due to prolonged exposure to the detrimental conditions. It is possible that some forms of idiopathic sexual precocity in non-migrating children involve similar disorders of programming processes to some extent. A common early pathophysiological insult could also play some role in the long-term psychosocial dysfunction that would then be associated with sexual precocity, but not necessarily result from this early maturational process.

\section{Acknowledgements}

We are grateful to Prof Dr F de Zegher for helpful discussion and criticisms. Anne-Simone Parent is a research fellow of the Belgian 'Fonds National de la Recherche Scientifique' (FNRS). Parts of this work are supported by the FRSM (grants 3.4515 .01 and 3.4573.05), the European Commission (EDEN project, contract QLRT-2001-00 269), and the Belgian Study Group for Pediatric Endocrinology.

\section{References}

1 Gluckman PD, Cutfield W, Hofman P \& Hanson MA. The fetal, neonatal, and infant environments - the long-term consequences for disease risk. Early Human Development 200581 51-59.
2 Parent AS, Teilmann G, Juul A, Skakkebaek N, Toppari J \& Bourguignon JP. The timing of normal puberty and the age limits of sexual precocity: variations around the world, secular trends and changes after migration. Endocrine Reviews 200324 668-693.

3 Slyper AH. The pubertal timing controversy in the USA, and a review of possible causatuive factors for the advance ion timing of onset of puberty. Clinical Endocrinology $2006651-8$.

4 Gluckman PD \& Hanson MA. The consequences of being born small- an adaptative perspective. Hormone Research $2006 \mathbf{6 5}$ (Suppl 3) 5-14.

5 Cooper C, Kuh D, Egger P, Wadsworth M \& Barker D. Childhood growth and age at menarche. British Journal of Obstetrics and Gynaecology $1996 \mathbf{1 0 3} 814-817$.

6 Barker DJP. The developmental origins of well-being. Philosophical Transactions of the Royal Society of London. Series B 2004359 1359-1366.

7 Tam CS, de Zegher F, Garnett SP, Baur LA \& Cowell CT. Opposing influences of prenatal and postnatal growth on the timing of menarche. Journal of Clinical Endocrinology and Metabolism 2006 (in press).

8 Gluckman PD \& Hanson MA. Evolution, development and timing of puberty. Trends in Endocrinology and Metabolism 200617 7-12.

9 Gluckman PD \& Hanson MA. Changing times: the evolution of puberty. Molecular and Cellular Endocrinology 2006 (in press).

10 Litt IF. The interaction of pubertal and psychosocial development during adolescence. Pediatric Reviews 199112249.

11 Tanner JM. Growth at Adolescence. 2nd edn Oxford: Blackwell, 1962.

12 Grumbach MM \& Styne DM. Puberty: ontogeny, neuroendocrinology, physiology, and disorders. In Williams' Textbook of Endocrinology, 9th edn, pp 1509-1625. Eds JD Wilson, DW Foster, HM Kronenberg \& PR Larsen, Philadelphia: WB Saunders Co, 1998.

13 Marshall WA \& Tanner JM. Variations in the pattern of pubertal changes in boys. Archives of Disease in Childhood 197046 13-23.

14 Tanner JM \& Whitehouse RH. Clinical longitudinal standards for height, weight, height velocity, weight velocity, and stages of puberty. Archives of Disease in Childhood 197651 170-179.

15 Lee PA, Guo SS \& Kulin HE. Age of puberty: data from the United States of America. Acta Pathologica, Microbiologica, Immunologica Scandinavica 2001109 81-88.

16 Sklar CA, Kaplan SL \& Grumbach MM. Evidence for dissociation between adrenarche and gonadarche: studies in patients with idiopathic precocious puberty, gonadal dysgenesis, isolated gonadotropin deficiency, and constitutionally delayed growth and adolescence. Journal of Clinical Endocrinology and Metabolism $198051548-556$.

17 Palmert MR, Hayden DL, Mansfield MJ, Crigler JF, Jr, Crowley WF, Jr Chandler DW \& Boepple PA. The longitudinal study of adrenal maturation during gonadal suppression: evidence that adrenarche is a gradual process. Journal of Clinical Endocrinology and Metabolism $2001864536-4542$.

18 Marti-Henneberg C \& Louw GJ. Average menarcheal age of higher socioeconomic status urban Cape coloured girls assessed by means of status quo and recall methods. American Journal of Physical Anthropology 199596 1-5.

19 Koo MM \& Rohan TE. Accuracy of short-term recall of age at menarche. Annals of Human Biology 199724 61-64.

20 Artaria MD \& Marti-Henneberg C. Why did they lie? Socioeconomic bias in reporting menarcheal age Annals of Human Biology 200027 561-569.

21 de Ridder CM, Thijssen JH, Bruning PF, Van den Brande JL, Zonderland ML \& Erich WB. Body fat mass, body fat distribution, and pubertal development: a longitudinal study of physical and hormonal sexual maturation of girls. Journal of Clinical Endocrinology and Metabolism 199275 442-446.

22 Bourguignon JP. Linear growth as a function of age at onset of puberty and sex steroid dosage: therapeutic implications. Endocrine Reviews $19889467-488$. 
23 Marti-Henneberg C \& Vizmanos B. The duration of puberty in girls is related to the timing of its onset. Journal of Pediatrics $1997 \mathbf{1 3 1}$ 618-621.

24 Compas BE, Hinden BR \& Gerhardt CA. Adolescent development: pathways and processes of risk and resilience. Annual Review of Psychology 199546 265-293.

25 Dick DM, Rose RJ, Pulkkinen L \& Kaprio J. Measuring puberty and understanding its impact: a longitudinal study of adolescent twins. Journal of Youth and Adolescence 200130385.

26 Hergenroeder AC, Hill RB, Wong WW, Sangi-Haghpeykar H \& Taylor W. Validity of self-assessment of pubertal maturation in African-American and European-American adolescents. Journal of Adolescent Health $1999 \mathbf{2 4} 201-205$.

27 Petersen AC, Tobin-Richards $M$ \& Boxer A. Puberty: its measurement and its meaning. Journal of Early Adolescence 1983 3 47-62.

28 Morris NM \& Udry JR. Validation of a self-assessment instrument to assess stage of adolescent development. Journal of Youth and Adolescence 19809 271-280.

29 Duke PM, Litt IF \& Gross RT. Adolescents' self-assessment of sexual maturation. Pediatrics 198066 918-920.

30 Schlossberger NM, Turner RA \& Irwin CE. Validity of self-report of pubertal maturation in early adolescents. Journal of Adolescent Health 199213 109-113.

31 Moriac S. Self-assessment of pubertal stages in overweight children. Pediatrics $2002110743-747$.

32 Hick KM \& Katzman DK. Self-assessment of sexual maturation in adolescent females with anorexia nervosa. Journal of Adolescent Health 199924 206-211.

33 Finkelstein JW, D'Arcangelo MR, Susman EJ, Chinchilli VM, Kunselman SJ, Schwab J, Demers LM, Liben LS \& Kulin HE. Selfassessment of physical maturation in boys and girls with delayed puberty. Journal of Adolescent Health 199925 379-381.

$34 \mathrm{Wu}$ Y, Schreiber JB, Klementowicz V, Biro F \& Wright D. Racial differences in accuracy of self-assessment of sexual maturation among young black and white girls. Journal of Adolescent Health 200128 197-203.

35 Berg-Kelly K \& Erdes L. Self-assessment of sexual maturity by midadolescents based on a global question. Acta Paediatrica 199786 10-17.

36 Brooks-Gunn J, Warren MP, Rosso J \& Gargiulo J. Validity of selfreport measures of girls - pubertal status. Child Development 1987 58 829-841.

37 Xhrouet-Heinrichs D, Lagrou K, Heinrichs C, Craen M, Dooms L, Malvaux P, Kanen F \& Bourguignon J-P. Longitudinal study of behavioral and affective patterns in girls with central puberty during long-acting triptorelin therapy. Acta Paediatrica $1997 \mathbf{8 6}$ 808-815.

38 Proos LA, Hofvander Y \& Tuvemo T. Menarcheal age and growth pattern of Indian girls adopted in Sweden. I. Menarcheal age. Acta Paediatrica Scandinavica $1991 \mathbf{8 0} 852-858$.

39 Bourguignon JP, Gerard A, Alvarez Gonzalez ML, Fawe L \& Franchimont P. Effects of changes in nutritional conditions on timing of puberty: clinical evidence from adopted children and experimental studies in the male rat. Hormone Research 1992 38 (Suppl 1) 97-105.

40 Oostdijk W, Yap YN, Slijper FME, Wit JM \& Drop SLS. Puberteit en eindlengte bij uit het buitenland geadopteerde kinderen. Tijdschrift Kindergeneeskunde 199664 39-43.

41 Virdis R, Street ME, Zampolli M, Radetti G, Pezzini B, Benelli M, Ghizzoni L \& Volta C. Precocious puberty in girls adopted from developing countries. Archives of Disease in Childhood $1998 \mathbf{7 8}$ 152-154.

42 de Monleon JV, Geneste B \& Huet F. Puberté précoce chez les enfants adoptés, un risque à ne pas oublier. Archives de Pédiatrie 19996 589-590.

43 Baron S, Battin J, David A \& Limal JM. Puberté précoce chez des enfants adoptés de pays étrangers. Archives de Pédiatrie 20007 809-816.

44 Krstevska-Konstantinova M, Charlier C, Craen M, Du Caju M, Heinrichs C, de Beaufort C, Plomteux G \& Bourguignon JP. Sexual precocity after immigration from developing countries to Belgium: evidence of previous exposure to organochlorine pesticides. Human Reproduction 200116 1020-1026.

45 Teilmann G, Main K, Skakkebaek N \& Juul A. High frequency of central precocious puberty in adopted and immigrant children in Denmark. Hormone Research 200258 (Suppl 2) 135

46 Mason PW, Narad C, Jester T \& Parks J. A survey of growth and development in the internationally adopted child. (Abstract) Pediatric Research 200047 209A.

47 Mul D, Oostdijk W \& Drop SLS. Early puberty in adopted children. Hormone Research 200257 1-9.

48 Vercauteren M \& Susanne $\mathrm{C}$. The secular trend of height and menarche in Belgium: are there any signs of a future stop? European Journal of Pediatrics 1985144 306-309.

49 Roelants M \& Hauspie R. at http://www.vub.ac.be/groeicurven in role of environmental factors in timing the onset and progression of puberty. International Jouirnal of Andrology $200629286-290$.

50 Michaud PA, Suris JC \& Deppen A. Gender specific psychosocial correlates of pubertal timing in a national sample of Swiss adolescents. Molecular and Cellular Endocrinology 2006255 $172-178$

51 Patton GC, McMorris BJ, Toumbourou JW, Hemphill SA, Donath S \& Catalano RF. Puberty and the onset of substance use and abuse. Pediatrics 2004114 303-306.

52 Stattin $\mathrm{H} \&$ Magnusson D. Pubertal maturation in female development. Lawrence Erlbaum Associates, Publishers, 1990.

53 Berg-Kelly K \& Eriksson J. Adaptation of adopted foreign children at mid-adolescence as indicated by aspects of health and risk taking - a population study. European Childhood $\mathcal{E}$ Adolescent Psychiatry 19976 199-206.

54 Schore AN. Dysregulation of the right brain: a fundamental mechanism of traumatic attachment and the psychopathogenesis of posttraumatic stress disorder. Australian and New Zealand Journal of Psychiatry 200236 9-30.

55 Schore AN. Attachment, affect regulation and the developing right brain: linking developmental neuroscience to pediatrics. Pediatrics in Reviews 200526 204-211.

56 Powley TL \& Laughton W. Neural pathways involved in the hypothalamic integration of autonomic responses. Diabetologia 198120 (Suppl) 378-387.

57 Mark LP, Daniels DL, Naidich TP \& Hendrix LE. Limbic connections American Journal of Neuroradiology 199516 1303-1306.

58 Qing H \& Karlberg J. BMI in childhood and its association with height gain, timing of puberty, and final height. Pediatric Research $200149244-251$.

59 Bouret SG \& Simerly RB. Minireview: leptin and development of hypothalamic feeding circuits. Endocrinology $2004 \mathbf{1 4 5}$ 2621-2626.

60 Bouret SG, Draper SJ \& Simerly RB. Trophic action of leptin on hypothalamic neurons that regulate feeding. Science 2004304 108-110.

61 Giedd JN. Structural magnetic resonance imaging of the adolescent brain. Annals of the New York Academy of Sciences 20041021 77-85.

62 Giedd JN, Vaituzis AC, Hamburger SD, Lange N, Rajapakse JC, Kaysen D, Vauss YC \& Rapoport JL. Quantitative MRI of the temporal lobe, amygdala, and hippocampus in normal human development: ages 4-18 years. Journal of Comparative Neurology $1996366223-230$.

63 Rasier G, Toppari J, Parent AS \& Bourguignon JP. Female sexual maturation and reproduction after prepubertal exposure to estrogens and endocrine disrupting chemicals: a review of rodent and human data. Molecular and Cellular Endocrinology 2006 155 187-201.

64 Morreale de Escobar G, Obregon MJ \& Escobar del Rey F. Role of thyroid hormone during early brain development. European Journal of Endocrinology 2004151 U25-U37.

65 Colborn T. Neurodevelopment and endocrine disruption. Environmental Health Perspectives 2004112 944-949. 
66 Proos LA. Anthropometry in adolescence - secular trends, adoption, ethnic and environmental differences. Hormone Research 199339 (Suppl 3) 18-24.

67 Teicher MH, Dumont NL, Ito Y, Vaituzis C, Giedd JN \& Andersen SL. Childhood neglect is associated with reduced corpus callosum area. Biological Psychiatry 200456 80-85.

68 Mason P \& Narad C. Long-term growth and puberty concerns in international adoptees. Pediatric Clinics of North America 200552 1351-1368.

69 Chicoine JF, Germain P, Lemieux J. L'enfant adopté dans le monde en quinze chapitres et demi. 2003 Les éditions de l'Hôpital Sainte Justine, Montréal, Québec, Canada.

70 Johnson DE, Miller LC, Iverson S, Thomas W, Franchino B, Dole K, Kiernan MT, Georgieff MK \& Hostetter MK. The health of children adopted from Romania. Journal of the American Medical Association 1992268 3446-3451.

71 Pacak K \& Palkovits M. Stressor specificity of central neuroendocrine responses: implications for stress-related disorders. Endocrine Reviews 200122 502-548.

72 Rivest S \& Rivier $\mathrm{C}$. The role of corticotropin-releasing factor and interleukin-1 in the regulation of neurons controlling reproductive functions. Endocrine Reviews 199516 177-199.

73 Belsky J, Steinberg L \& Draper P. Childhood experience, interpersonal development and reproductive strategy: an evolutionary theory of socialization. Child Development 199162 647-670.

74 Wierson M, Long PJ \& Forehand RL. Toward a new understanding of early menarche: the role of environmental stress in pubertal timing. Adolescence 199328 913-924.

75 Schulz KM \& Sisk C. Pubertal hormones, the adolescent brain and the maturation of social behaviors: lessons from the Syrian hamster. Molecular and Cellular Endocrinology 2006154 120-126.

76 Walker SP, Chang SM, Powell CA \& Grantham-McGregor SM. Effects of early childhood psychosocial stimulation and nutritional supplementation on cognition and education in growth-stunted Jamaican children: prospective cohort study. The Lancet 2005366 1804-1807.

77 Proos LA, Hofvander Y, Wennqvist K \& Tuvemo T. A longitudinal study on anthropometric and clinical development of Indian children adopted in Sweden. I. Clinical and anthropometric condition at arrival. Upssala Journal of Medical Sciences 199297 79-92.

78 Ibanez L \& de Zegher F. Puberty and prenatal growth. Molecular and Cellular Endocrinology $200615422-25$.

79 Mallard C, Loeliger M, Copolov D \& Rees M. Reduced number of neurons in the hippocampus and the cerebellum in the post natal guinea-pig following intrauterine growth-restriction. Neuroscience $2000100327-333$.

80 Dieni S \& Rees M. Dendritic morphology is altered in hippocampal neurons following prenatal compromise. Journal of Neurobiology 200355 41-52.

81 Tolsa CB, Zimine S, Warfield SK, Freschi M, Rossignol AS, Lazeiras F, Hanquinet S, Pfizenmaier M \& Hüppi PS. Early alteration of structural and functional brain development in premature infants born with intrauterine growth retardation. Pediatric Research 200456 132-138.

82 Ibanez L, Valls C, Ong K, Dunger DB \& de Zegher F. Metformin therapy during puberty delays menarche, prolongs pubertal growth, and augments adult height: a randomized study in lowbirth-weight girls with early-normalm onset of puberty. Journal of Clinical Endocrinology and Metabolism 200691 2068-2073.
83 Ibanez L, Ong K, Valls C, Marcos MV, Dunger DB \& de Zegher F. Metformin treatment to prevent early puberty in girls with perecocious pubarche. Journal of Clinical Endocrinology and Metabolism 2006 (in press).

84 Vickers MH, Gluckman PD, Coveny AH, Hofman PL, Cutfield WS, Gertler A, Breier BH \& Harris M. Neonatal leptin treatment reverses developmental programming. Endocrinology 2005146 4209-4210.

85 Balthazart J \& Ball GF. Is brain estradiol a hormone or a neurotransmitter? Trends in Neuroscience $200629241-249$.

86 Matagne V, Rasier G, Lebrethon MC, Gérard A \& Bourguignon JP. Estradiol stimulation of pulsatile gonadotropin releasing hormone secretion in vitro: correlation with perinatal exposure to sex steroids and induction of sexual precocity in vivo. Endocrinology $20041452775-2783$.

87 Zoeller RT, Dowling ALS, Herzig CTA, Iannacone EA, Gauger KJ \& Bansal R. Thyroid hormone, brain development and the environment. Environmental Health Perspectives $2002 \mathbf{1 1 0}$ (Suppl 3) 355-361.

88 Panzica GC, Viglietti-Panzica C \& Ottinger MA. Introduction: neurobiological impact of environmental etrogens. Brain Research Bulletin 200565 187-191.

89 Patisaul HB. Phytoestrogen action in the adult and developing brain. Journal of Neuroendocrinology 200517 57-64.

90 Rose AB, Merke DP, Clasen LS, Rosenthal MA, Wallace GL, Vaituzis AC, Fields JD \& Giedd JN. Effects of hormones and sex chromosomes on stress-influenced regions of the developing pediatric brain. Annals of the New York Academy of Sciences 2004 1032 231-233.

91 Panzica GC, Balthazart J, Pessatti M \& Viglietti-Panzica C. The parvocellular vasotocin system of Japanese quail: a developmental and adult model for the study of influences of gonadal hormones on sexually differentiated and behaviorally relevant neural circuits. Environmental Health Perspectives 2002110 (Suppl 3) 423-428.

92 Viglietti-Panzica C, Montoncello B, Mura E, Pessatti M \& Panzica GC. Organizational effects of diethylstilbestrol on brain vasotocin and sexual behavior in male quail. Brain Research Bulletin $200565225-233$.

93 Delemarre-van de Waal HA, van Coeverden SCCM \& Engelbregt MJT. Factors affecting onset of puberty. Hormone Research 200257 (Suppl 2) 15-18.

94 Weiss B. Sexually dimorphic nonreproductive behaviors as indicators of endocrine disruption. Environmental Health Perspectives 2002110 (Suppl 3) 387-391.

95 Anasti JN, Flack MR, Froelich J, Nelson LM \& Nisula BC. A potential novel mechanism for precocious puberty in juvenile hypothyroidism. Journal of Clinical Endocrinology and Metabolism 199580 (Suppl 3) 276-279.

96 Asami T, Kikuchi T, Kamimura T, Kinoshita S \& Uchiyama M. Precocious puberty in a girl with congenital hypothyroidism receiving continuous L-thyroxine therapy. Pediatrics International 200143 87-90.

97 Dunn JT \& Delange F. Damaged reproduction: the most important consequence of iodine deficiency. Journal of Clinical Endocrinology and Metabolism 200186 2360-2363.

Received 30 June 2006

Accepted 14 July 2006 